\title{
Subjetivação na formação em Psicanálise: uma análise institucional de discurso ${ }^{\star}$
}

\author{
Renee Volpato Viaro, ${ }^{I}$ Marlene Guirado, ${ }^{I I} \star \star \star L u c i a n a ~ A l b a n e s e^{I I I}$ \\ ${ }^{I}$ Pontifícia Universidade Católica do Paraná, Curitiba, PR, Brasil \\ ${ }^{I I}$ Universidade de São Paulo, São Paulo, SP, Brasil \\ III Universidade Federal do Paraná, Curitiba, PR, Brasil
}

\begin{abstract}
Resumo
Esta pesquisa problematiza os efeitos subjetivos experienciados pelo psicanalista no processo de formação em psicanálise; visando, portanto, a investigar possiveis modos de subjetivação nos discursos sobre este processo. Para isso, foram entrevistados seis psicanalistas: três lacanianos e três vinculados à Associação Internacional de Psicanálise - IPA; as entrevistas foram transcritas e analisadas segundo a metodologia da Análise Institucional do Discurso. Pôde-se delinear como os entrevistados vinculados à IPA subjetivam-se através de uma reafirmação do discurso formador, reconhecendo-se psicanalistas na/pela observância ao modelo de formação da IPA; e os lacanianos através de uma contraposição a outros discursos, reconhecendo-se psicanalistas na/ pela diferenciação a termos associados à IPA, à filosofia, à psicologia, etc. Ainda dentre os resultados, a análise pessoal figura, em ambos os grupos, como dispositivo central de produção do psicanalista: uma relação produtora de verdades e saberes de si nos quais os entrevistados encontram condições e limites para se reconhecerem psicanalistas.
\end{abstract}

Palavras-chave: modos de subjetivação; formação psicanalítica; discurso; análise institucional do discurso; assujeitamento-resistência.

\section{Subjectivity in Psychoanalytic formation: an institutional discourse analysis}

\begin{abstract}
This research discusses the subjective effects experienced by the psychoanalyst in the process of psychoanalytical formation; intended, therefore, to investigate possible modes of subjectivity in the discourses about this process. For this, have been interviewed six psychoanalysts: three Lacanian and three linked to International Psychoanalytical Association - IPA; the interviews were transcribed and analyzed according to Institutional Discourse Analysis. It was possible to delineate how respondents linked to IPA subjective themselves through a reaffirmation of the trainer discourse, recognizing up as psychoanalysts by the observance of the IPA's training model; and the Lacanians through a contraposition to other discourses, recognizing up as psychoanalysts by the differentiation to the terms associated with IPA, philosophy, psychology, etc. Still among the results, the personal analysis appeared, in both groups, as the most important production device of the psychoanalyst: a relationship that produces truths and knowledge of self in which respondents find conditions and limitations to recognize themselves as psychoanalysts.
\end{abstract}

Keywords: modes of subjectivity; psychoanalytical formation; discourse; institutional discourse analysis; subjection-resistance.

\section{Introdução}

Desde Freud, o saber psicanalítico é produzido e reproduzidodemaneirasparticulares. Dodesenvolvimento de uma escuta da sintomatologia histérica aos escritos que tal prática gerou, criou-se não apenas um modo de se clinicar e compreender o dito psiquismo, mas também todo um processo de legitimação de um campo de saber, de um método, um objeto, de personalidades e seus respectivos grupos, etc. Certas práticas, certas relações, repetem-se, então, em seus padrões básicos e ganham, com isso, aos olhos daqueles que as fazem, legitimidade e naturalidade (GUIRADO, 2000).

$\mathrm{Na}$ (re)produção dessas práticas, viu-se o próprio campo psicanalítico sofrer rupturas e reorganizações que inauguraram modelos de formação distintos; dentre eles, mais reconhecidamente o proposto pela Associação Internacional de Psicanálise (IPA) e pelo ensino de Jaques Lacan. Tendo em vista o tensionamento delineado

^ Trabalho desenvolvido com o apoio da Fundação Araucária de Apoio ao Desenvolvimento Científico e Tecnológico do Estado do Paraná

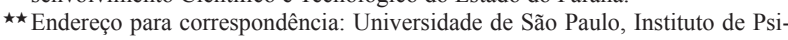
cologia, Departamento de Psicologia da Aprendizagem do Desenv. da Personalidade. Av. Prof. Mello Moraes, 1721 - Cidade Universitária. São Paulo, SP - Brasil. CEP: 05508-030.E-mail: reneevolpato@yahoo.com.br,mguirado@ terra.com.br, lu5valore@gmail.com pelas fronteiras entre esses diferentes discursos, passouse a se problematizar os possíveis efeitos disso sobre aqueles que se propunham a trilhar um percurso dito psicanalítico: como, em sua formação, o psicanalista torna-se constitutivamente marcado pelos tensionamentos presentes no campo no qual está inserido? Como estas marcas se colocam em descontinuidade em relação a outras propostas de formação, expressando aquilo que é próprio de um modelo (sua especificidade) e, paralelamente, em continuidade em relação às demais propostas, expressando aquilo que é comum ao campo psicanalítico (sua unidade)? Foi assim que esta pesquisa buscou investigar possíveis efeitos subjetivos, ou ainda, possíveis modos de subjetivação presentes nos discursos sobre o processo de formação em psicanálise: tomando, por hipótese, a ideia de que as diferenças e igualdades entre estes modelos de formação atravessariam também o psicanalista que assim se forma em meio a este campo fronteiriço/unitário, como sua resultante e seu agente promotor.

Para conduzir tal proposta não se recorreu a uma revisão teórica acerca da formação em psicanálise, como fazem muitos estudos sobre o tema (SARAIVA; NUNES, 2007). Embora se reconheça a importância da 
proposta, resgatar os princípios autorais e conceituais que norteiam a(s) formação(ões) em psicanálise não esteve no escopo de interesses desta pesquisa. Pela necessidade de estabelecimento de um recorte que instrumentalizasse a problemática levantada, buscou-se investigar tais modos de subjetivação junto àqueles que experienciam tal formação concretamente - daí parte da originalidade desta pesquisa. Para tanto, foram entrevistados seis psicanalistas (três lacanianos e três vinculados à IPA) que se reconhecem como tendo feito ou estando em processo de formação em psicanálise. Distanciando-se da possibilidade de simplificar ou até mesmo anular a pluralidade e complexidade que anima o campo psicanalítico, o recorte em torno do modelo de formação lacaniano e do da IPA se deu pelo amplo reconhecimento histórico de que desfrutam, sendo consideradas as principais propostas estruturadas de formação psicanalítica (DASSOLER, 2005), e também por se apresentarem como os modelos de maior presença e relevância na geografia na qual esta pesquisa foi elaborada (Curitiba). As entrevistas foram integralmente transcritas e analisadas segundo a perspectiva da Análise Institucional do Discurso (AID), sobre a qual trataremos na sequência.

Ao estudar um discurso (que os psicanalistas produzem sobre a formação) por meio de outro (da AID) entendemos que criamos oportunidade para contraposição de perspectivas acerca de temas, consideramos, bastante instituídos e legitimados. De forma a estabelecer um debate que contorna, em alguma medida, a auto-referência de um discurso por permitir que os comentários e afirmações produzidos em situação de entrevista possam ser lidos por lentes diversas daquelas utilizadas pelos entrevistados. Espera-se, desta forma, trazer à baila aspectos presentes, porém, nem sempre discutidos numa formação de modo a contribuir na mobilização de arranjos solidificados.

\section{A Análise Institucional do Discurso como Perspectiva Teórico-Metodológica ${ }^{1}$}

Desenvolvida por Marlene Guirado, pesquisadora e professora livre-docente do Instituto de Psicologia da Universidade de São Paulo, a AID configura, ao invés de um corpo teórico com proposições prévias acerca de seu objeto de estudo, um campo conceitual capaz de viabilizar um método de análise. Apoiada nos pensamentos de Freud, Foucault, Maingueneau e Albuquerque, Guirado elabora uma interface possível entre conceitos específicos desses autores - uma organização de ideias - naquilo que a psicanálise freudiana, o pensamento foucaultiano, a linguística de Maingueneau e a análise institucional de Albuquerque podem, pontual e estrategicamente, serem aproximadas para dar forma a uma analítica da subjetividade (GUIRADO, 2010). Razão pela qual esta pesquisa (um trabalho que versa sobre modos de subjetivação) elegeu a AID como referencial de análise.

Para maiores detalhes acerca da discussão metodológica remetemos o leitor a Viaro e Valore (2011).
Para os fins da exposição que se segue, daremos destaque a três dos principais operadores conceituais envolvidos na fundamentação da AID, quais sejam, "instituição", "discurso" e "sujeito".

Antecipemos que por "institucional" não se compreende, como é comum na psicologia, uma área de trabalho voltada à intervenção em instituições concretas, mas antes, à instituição de modos de se relacionar. Embora a AID tenha, em termos de desenvolvimento histórico, elos com as propostas institucionais de pensadores como José Bleger (1984) e George Lapassade (1977), seu principal marco e ponto de apoio para a delimitação do conceito de "instituição" é derivado de Guilhon Albuquerque (1978), com o qual o termo designa um conjunto de práticas e relações sociais que se repetem e, assim, se legitimam disparando efeitos de reconhecimento da naturalidade dessas formas de se relacionar e desconhecimento de sua relatividade (ALBUQUERQUE, 1978; GUIRADO, 2010). Portanto, quando pensada como instituição, a formação em psicanálise toma a forma de uma organização de práticas e relações que, graças à sua repetição, se solidifica, perante os olhos daqueles que a fazem, como única organização legítima para o advento do psicanalista e consequente prática da psicanálise; promovendo, de quebra, o desconhecimento da relatividade de semelhantes arranjos, assim como da legitimidade de outras propostas.

É valido salientar que as relações institucionais tomadas como objeto pela AID não são as relações tal como materialmente se dão e sim, em aproximação à psicanálise, "tal como imaginadas, percebidas, representadas pelo sujeito. [...] o universo de suas representações e afetos" (GUIRADO, 1986, p. 71-72). Daí focarmos, em nossas análises, as cenas a respeito do processo de formação que os entrevistados configuram na situação de entrevista, uma vez que elas dizem das relações e práticas de uma formação psicanalítica tal como imaginadas, percebidas, representadas, sentidas; enfim, tal como reconhecidas e desconhecidas pelos psicanalistas participantes. É, então, com base na cenografia traçada em entrevista que podemos delinear os efeitos subjetivos - de reconhecimento e desconhecimento - de se fazer psicanalista (e, então, fazer psicanálise) através de uma dada "instituição psicanálise" e não de outra (em referência aos modelos propostos pela IPA e pela escola lacaniana). Assim, situa-se melhor por que a análise institucional então empreendida dá foco aos processos de subjetivação imbricados na formação psicanalítica, e não a uma análise do funcionamento das instituições concretas de formação ou da própria psicanálise como campo de produção de saber. Apontase, ainda, que as relações objeto desta pesquisa são, por serem institucionais, também discursivas.

Para uma melhor apreciação desta paridade é necessário situar a concepção de discurso com a qual se trabalha na AID. Adentrando o âmbito das ideias de Foucault (2008) e Maingueneau (1997), entende-se que discursar é mais que representar em palavras uma dada realidade externa ou interna. $\mathrm{O}$ discurso, segundo uma 
concepção pragmática, além de representar, integra a realidade, sendo ele mesmo parte da realidade que numa concepção tradicional ele somente representaria. Discurso é, pois, um dispositivo social que posiciona os falantes permitindo-lhes produzir afirmações a partir de um dado lugar ao mesmo tempo em que constrange a produção de possibilidades outras (MAINGUENEAU, 1997; GUIRADO, 2000). Logo, quando tomada como discurso, a formação em psicanálise constitui um dispositivo situado no tempo e no espaço que posiciona os falantes possibilitando-lhes a reprodução de um dado discurso (que os possibilita se reconhecer psicanalistas); isso ao mesmo tempo em que os diversos exercícios do discurso psicanalítico estão constantemente reanimando, recriando, o dispositivo que os constituiu. Ou seja, o psicanalista não somente reproduz a psicanálise como se habitasse uma exterioridade sua, mas também a produz ativamente enquanto é por ela produzido. Tal como na "instituição", no "discurso" tem-se uma relação de interioridade entre instituição/discurso e agente institucional/falante. Tratam-se, na AID, de noções que guardam uma relação de paridade uma com a outra, permitindo o trânsito pontual entre uma análise institucional e uma análise de discurso.

Avançando ao terceiro operador conceitual de nossa exposição, o "sujeito", remetemos a Foucault (1995, p. 231), quando afirma que o objetivo de seu trabalho "foi criar uma história dos diferentes modos pelos quais, em nossa cultura, os seres humanos tornaram-se sujeitos". Foucault põe em evidência como suas objetivações se dão no interior de um conjunto de práticas discursivas, histórica e geograficamente situadas, ao invés de propor, conforme algumas teorias, a existência de uma espécie de fundamento humano que tivesse sido mascarado, alienado ou aprisionado em mecanismos de repressão a partir de processos históricos, econômicos, familiares e/ou sociais.

Munidos dessa compreensão, entendemos que o psicanalista é objetivado no e pelo dispositivo de formação, isto é, ele acontece mediante práticas discursivo-institucionais que o constituem ao mesmo tempo em que lhe fornecem uma espécie de crivo de reconhecimento de si, um modo de se reconhecer e, assim, se subjetivar. Alguém se faz psicanalista através da sujeição a um conjunto de regras e exigências cujo atendimento é imprescindível para seu advento. De modo que fora dessa organização, isto é, sem o atendimento às regras de enunciação ali vigentes, não há psicanalista - não se vê e não é reconhecido como tal. Entretanto, se o dispositivo discursivo-institucional assujeita, não devemos perder de vista que ele é constantemente recondicionado pela prática dos psicanalistas; donde se abre possibilidade para movimentos de resistência ao discurso instituído. Assim, instaura-se um jogo que vai do polo do assujeitamento ao da resistência à ordem discursiva vigente ${ }^{2}$ (FOUCAULT, 2009b). Esperamos

\footnotetext{
${ }^{2}$ Lembrando que "assujeitamento" não expressa algum um tipo de aprisionamento a ser extinto, mas condição para a objetivação de qualquer sujeito, assim como "resistência" não remete ao processo descrito por Freud; ambos dizem dos jogos de força presentes em qualquer relação, conforme Foucault.
}

com isso comunicar que o sujeito, segundo nos informa Foucault e subscreve a AID, é produzido por e num determinado discurso, não existindo fora dele.

Até aqui expomos como um sujeito dá-se no horizonte dos processos de objetivação e subjetivação conforme delineados no discurso foucaultiano. Contudo, se a AID almeja uma análise da subjetividade é preciso avançar na matização dos modos de subjetivação apontados por Foucault. Pois se é verdade que todo psicanalista constituise no jogo de assujeitamento/resistência à psicanálise (tomada como dispositivo discursivo-institucional), é igualmente verdadeiro que cada psicanalista o fará a seu modo, de acordo com os trilhos de sua história de vida. É, então, visando considerar os modos de subjetivação naquilo que têm de radicalmente singular que Guirado (1995; 2010) proporá um conceito dobradiça de sujeito - um operador conceitual capaz de matizar a subjetivação um tanto geral e indiferenciada esboçada por Foucault com as cores da singularidade de uma história de vida - objetivando, assim, uma analítica do domínio subjetivo (RIBEIRO, 2007).

O sujeito-dobradiça não é um sujeito especial que se superpõe, opõe ou justapõe ao sujeito psíquico, à pessoa, ou ao sujeito da ação numa oração linguística. [...] se trata de uma metáfora que empresta as qualidades da imagem para apresentar o jogo entre contexto e singularidade numa situação de fala (GUIRADO, 2010, p. 155).

O acionamento desta metáfora permitirá, portanto, a articulação entre dispositivos discursivo-institucionais (objetivantes) e o modo como cada um se insere e passa a se reconhecer nesses e por esses dispositivos (subjetivação) ao longo de sua história. Tomando a formação psicanalítica como exemplo, podemos pensar os dispositivos discursivo-institucionais que constituirão o psicanalista (seminários, cartéis, supervisões, estudos, análise pessoal, etc.) aliados ao modo como cada psicanalista adentrará tais dispositivos e, por que não, os modificará ao atribuir-lhes acentuação própria proveniente de suas experiências de vida. Isto quer dizer que um dado psicanalista atualiza modos de subjetivação provenientes de dispositivos experienciados anteriormente quando adentra sua formação. Assim, efeitos anteriores de reconhecimento e desconhecimento vão sendo sobrepostos e reacomodados ao longo de um percurso de vida sempre marcado pelos diferentes dispositivos discursivoinstitucionais vivenciados por uma pessoa numa época e numa sociedade específicas - do seio familiar às odes de formação psicanalítica (GUIRADO, 2010).

Dessa maneira, entende-se que o contexto imediato de entrevista constitui, ele mesmo, um dispositivo discursivo-institucional que dita condições de produção de discursos e de efeitos subjetivos que se darão por meio dos crivos de reconhecimento e desconhecimento propiciados pelo dispositivo em pauta; pelas atualizações de vivências anteriores que esse dispositivo permite (como, por exemplo, acerca do que é fazer uma formação em psicanálise ou uma pesquisa acadêmica); bem como pela reapropriação que os parceiros de fala ali implicados fazem desse mesmo dispositivo. É por isso que nossas análises remetem aos efeitos subjetivos produzidos 
no e pelo dispositivo da entrevista, isto é, dizem do psicanalista, da formação em psicanálise, do entrevistador, enfim, dos sentidos passiveis de serem configurados no contexto daquela(s) entrevista(s), não fora dele. Isso por entendermos que os sentidos não são propriedades dos falantes, à moda de um sujeito que os atribui, mas que tanto sentidos quanto sujeitos (psicanalista e entrevistador, em nosso caso) são, muito antes, resultantes do(s) contexto(s) que criam e se inserem.

A análise da cena discursiva que assim se faz privilegia o caráter performático do discurso, isto é, ao invés de se deter estritamente naquilo que o discurso diz, atenta para o que ele mostra enquanto diz:

Que tipo de interlocução se cria, que posição se legitima na asserção feita, que posição se atribui ao interlocutor, o jogo de expectativas criado na situação, como se respondem ou se subvertem tais expectativas, e assim por diante. [...] qualquer sentido a que se chegue será uma construção que considere todo esse modo de produção, ou melhor, o contexto (em) que (se) produz a fala e suas razões (seus sentidos) (GUIRADO, 2000, p. 34).

\section{Procedimentos Analítico-Metodológicos}

Com o intuito de assegurar sua randomização, a amostra deste estudo foi definida pela seleção tipo "bola de neve" (NICOLACI-DA-COSTA, 2007) na qual um entrevistado indica outro, e assim por diante; sendo apenas o primeiro entrevistado de cada grupo contatado por intermédio de um conhecido comum; não sendo, ainda assim, alguém com quem o entrevistador já tivesse contato prévio. Como critério de aceite/exclusão para participação na pesquisa, vigorou unicamente o reconhecimento que o entrevistado tenha de si mesmo alguém que tenha feito ou esteja fazendo uma formação psicanalítica. Sob pseudônimos temos, no grupo de psicanalistas da IPA: Helena (60 anos, psicóloga); Mario (48 anos, médico); e Vilma (66 anos, médica). Todos com formação psicanalítica junto a Sociedade Brasileira de Psicanálise (SBP) de grandes capitais brasileiras. No grupo lacaniano: Beatriz (36 anos, psicóloga); Larissa (45 anos, psicóloga); e Ricardo (43 anos, psicólogo). Todos com formação psicanalítica junto a diferentes escolas lacanianas de Curitiba.

Utilizou-se um roteiro de entrevista semiestruturado que versa sobre a relação do entrevistado com a psicanálise, seu percurso psicanalítico, o processo de formação, o psicanalista e os requisitos necessários para se falar em nome da psicanálise. Procedimentos que assegurassem o sigilo de identidade dos participantes e instituições foram adotados, bem como seu consentimento livre e esclarecido foi-nos assegurado mediante a assinatura de um termo.

Com base nas transcrições das entrevistas montamos cenas produzidas na relação entre psicanalista e entrevistador. Ao falar sobre seu percurso na psicanálise, nossos entrevistados mostram como a percebem desde os primeiros contatos, como se veem fazendo parte desta comunidade discursiva, como reconhecem o processo de formação, o que julgam necessário para ser um psicanalista, entre outros. Monta-se, enfim, cenas. E essas cenas do processo de formação que cada analista reconhece fazer passam a compor o gênero de discurso "entrevista acadêmica", o qual é escopo de nossa análise.

Esta atenção ao modo de produção dos enunciados remete aos princípios metodológicos da AID: entende-se que quaisquer afirmações realizadas no percurso de uma pesquisa estão constitutivamente atreladas ao seu modo de produção; em nosso caso, ao conjunto das entrevistas realizadas e à perspectiva analítica adotada. Outros caminhos poderiam ter sido trilhados, outras escolhas feitas e outros resultados obtidos. De modo que os sentidos aqui esboçados são relativos ao seu contexto de produção e cientes de sua parcialidade, não se propondo, portanto, a esgotar, simplificar nem generalizar o campo pesquisado.

As análises se deram em dois momentos: num primeiro em que cada entrevista foi considerada em sua singularidade e no qual configuramos cenas em que se pudessem destacar os efeitos de reconhecimento e desconhecimento presentes no discurso de cada entrevista (análise parcial). Perguntou-se: de que modo cada entrevistado, em seu discurso, reconhece e desconhece a si mesmo como psicanalista? E num segundo, em que as entrevistas de determinado grupo, depois de analisadas individualmente, foram comparadas de modo a permitir a identificação das regularidades discursivas, isto é, dos temas que se repetiram entre as diferentes entrevistas de um mesmo grupo de modo a evidenciar os eixos organizadores dos discursos sobre a formação num grupo e noutro (análise total). Perguntou-se: onde aqueles efeitos de reconhecimento e desconhecimento aproximam-se e distanciam-se entre os entrevistados de um mesmo grupo? E também entre um grupo e outro.

É a organização das regularidades temáticas de cada escola que apresentamos a seguir. Por razões econômicas, traremos extratos pontuais das entrevistas que ilustram didaticamente os temas que mais se repetiram nos discursos dos entrevistados, assim como são pontuais os enfoques analíticos que damos (muito mais poderia ser dito a respeito) - trata-se de uma síntese com vistas a expor o panorama geral da pesquisa. Discutiremos, ainda, algumas aproximações e distanciamentos possíveis entre os dois grupos por meio da comparação dos modos de organização de seus discursos.

Embora as falas dos entrevistados corram, na brevidade deste escrito, o risco de assumir um caráter estritamente ilustrativo (como se se prestassem meramente a subscrever uma conjectura que estaríamos a formular), é mister salientar que as análises apresentadas a seguir jamais estiveram em nosso horizonte prévio de hipóteses, sendo formuladas a partir dos discursos das entrevistas, e não numa espécie de antecipação que teria interpretado os dados de modo a reencontrar neles suposições já elaboradas.

Fractal, Rev. Psicol., v. 28 - n. 2, p. 275-284, 2016 


\section{Resultados e Análises: extratos demonstrativos}

\section{Aformação}

Quando estimulados a falar sobre o processo de formação (como é fazer uma formação em psicanálise, como foi a sua própria, como entendem que tal processo deve ser, de que modo poderia ou pode ser diferente se for o caso, etc.) os entrevistados vinculados à IPA discorrem basicamente sobre o programa de formação.

Assim, Helena descreve-se em face de exigências e requisições de toda sorte que, uma vez cumpridas, a qualificam como membro da Sociedade:

Tem uma seleção bem difícil pra poder entrar [...] Dai faz 1 ano de análise antes de começar os cursos, depois durante 4 anos a gente faz os cursos, que tem lá tudo programado: 4 anos de Freud, 2 anos de Melanie Klein, 2 anos de Bion e tem as matérias opcionais [...] durante todo o tempo a gente tem seminário clínico [...] a gente escreve um caso clínico inteirinho. São 2 casos, quer dizer que são 4 anos de supervisão [...] Se a gente passar nos 2 trabalhos, e se a gente passar nos cursos, tudo a gente tem avaliação, o tempo inteiro a gente está sendo avaliado, ai a gente recebe um certificado de membro associado da Sociedade.

Vilma destaca a importância do sistema de formação da IPA, a manutenção de sua base e evidencia a firmeza que seu cumprimento proporciona ao futuro psicanalista:

Olha, eu acho que o sistema da IPA é muito importante, muito útil e deve ser desse modo. [...] Ela [a pessoa] vai fazer seminários, que começam com Freud [...]. Porque cada curso tem, depois de cada autor, de cada curso, tem um material pra entregar, né, relatórios [...]. Então é uma formação longa, né, mas acho que é muito boa porque permite que a pessoa tenha muita firmeza depois daquilo que ela fala, né. [...] Olha, eu não acho que deva ser muito diferente, eu acho que o que ela é, ela éflexivel [...]. Mas eu acho que as mudanças que vão se fazendo são aquelas que são graduais, né, mas não de base, de base na exigência, por exemplo o tripé, o estudo teórico, a supervisão e a análise pessoal.

Os psicanalistas desse grupo descrevem a formação como um tipo de espaço de ordem composto por uma programação minuciosamente disposta temporal e numericamente, por processos seletivos e avaliativos, por estudos e exigências de base. Eé pela delongada exposição de semelhante modelo formativo que os entrevistados fazem-se reconhecer como psicanalistas "firmes" e devidamente certificados; ou ainda, demonstrando o processo avaliativo pelo qual passaram cria-se uma cena em que ao entrevistador é dada a oportunidade de apreciar a extensão das avaliações e exigências cumpridas em suas formações. A formação (e o psicanalista) acontece, em seus discursos, na medida em que o entrevistado (re) conhece, se submete e (re)produz esse espaço de ordem; o psicanalista e a psicanálise são por ele autenticados. As alusões a esse ordenamento são, ressaltemos ainda, diretas e afirmativas. A especificidade dessa organização discursiva ganha força quando comparada com o modo como a formação é caracterizada no discurso dos psicanalistas lacanianos. Vejamos.
Diante da mesma temática os lacanianos entrevistados reagem de forma bastante diversa. Ao discorrer sobre a formação tomam basicamente duas linhas argumentativas: dão destaque à análise pessoal e (enquanto o fazem) referenciam-se, via contraposição, a outras propostas formativas, a outros discursos que sustentariam um percurso com uma finalização delimitada. Beatriz, por exemplo, estende-se num discurso repleto de vozes que falam através da dela:

Eu jamais penso que eu tô pronta. Tô em formação, sempre, e, dai acho que tem que se implicar na formação [...] E não adianta, "vou fazer um curso de psicanálise", "eu vou fazer uma aula de psicanálise", "eu vou fazer uma faculdade de psicanálise". Acho que tem que ter implicação minha. Acho que tem que ser assim mesmo. [...] não tem formação concluída, se a psicanálise está sempre com essa visada da falta, se eu digo assim "agora eu tenho tudo", acabou né? Pra que fazer tanta formação pra chegar um dia e desaprender tudo. [...] autorização passa por saber que não sabe tudo, autorização por aí, né, mas não dizer assim, "agora eu tô pronto pra falar sobre um livro", "agora eu posso ensinar os outros", não dá né, aí... E autorização tem a ver com análise também né, autorização mais do que com o estudo é com a própria análise, vai junto.

Enquanto diz tudo o que a formação não é (não é curso, aula nem faculdade), que não se finaliza (como se um final fosse sinônimo de tudo ter e, assim, tudo desaprender), que alguém se autoriza psicanalista mediante não saber tudo (e não poder falar sobre um livro ou ensinar alguém) nem mediante o estudo unicamente; enquanto diz tudo o que a formação não é, dizíamos, Beatriz conta que o processo requer implicação própria e que autorizar-se psicanalista está associado à análise pessoal.

Larissa aludirá a um modelo imaginado para melhor desquitá-lo:

Eu imaginava que era como uma faculdade assim, né, uns

5 anos, 6 anos que você estuda e dai era como se você já precisasse estar pronta e eu não estava pronta ainda. Hoje já mudou um pouco nesse sentido, que não é a questão do tempo cronológico, é algo que é, que é mesmo vivendo, que não tem como. Então não adianta eu querer que fosse diferente.

Seu discurso sobre a formação, tal como o de Beatriz, traz as marcas de um jogo de contraposição em que a formação é dita num relance (trata-se de uma vivência) após o fim de toda uma fala sobre aquilo que ela não é (não é faculdade, não se dá pelo tempo cronológico e não adianta querer que fosse diferente).

Se junto aos entrevistados da IPA o psicanalista é qualificado na/pela programação disposta pela instituição (cursos, relatórios, supervisão, análise pessoal, trabalhos, entrevistas, avaliações, etc.), entre aqueles que fazem a formação lacaniana o psicanalista parece ser melhor qualificado justamente através da destituição de semelhantes programações. Ele se reconhece implicado na formação justamente quando não se vê fazendo cursos ou aulas de psicanálise. De forma análoga, os entrevistados ligados à IPA concebem um fim do processo de formação, ao passo que os lacanianos, além de não 
conceberem um fim de formação, reagem energicamente com menções a algum tipo de fim do processo. $\mathrm{O}$ fator "tempo" também recebe tratamento diametralmente oposto: no grupo da IPA encontramos diversas menções ao tempo de duração das diferentes atividades e do processo como um todo. Enquanto Larissa, representante do grupo lacaniano, traz experiências temporais de outra ordem, cujo fator de peso é uma vivência impossível de ser colocada em termos cronológicos.

O que vemos tomar forma é um jogo de contraposições que poderia ser encenado sob a forma de um debate, como se um entrevistado estivesse fazendo réplica à afirmação do outro. Entretanto, a cena não é bem essa. A oposição existe, mas usualmente ela parte dos psicanalistas lacanianos. Os entrevistados da escola inglesa priorizam à apresentação de suas programações, finalizações da formação, durações cronológicas, etc. Eles (re)afirmam o ordenamento discursivo que conhecem e que os permite se reconhecer psicanalistas. Já os entrevistados da escola francesa apresentam suas referentes concepções na contraposição a outros termos, como se estivessem implicados em se diferenciar de uma espécie de interlocutor imaginário. Não se diz tanto como a formação lacaniana é, diz-se antes o que ela não é (não é pautada em cursos, aulas...); não se diz que a formação não tem fim, diz-se que conceber um fim significa desconsiderar toda a formação; não se diz apenas que a formação refere-se a vivências, mas se diz também que isso não se dá numa cronologia; e assim por diante.

Com base nessas regularidades (e em outras que não puderam ser apresentadas) podemos lançar nosso argumento e, no contexto das entrevistas realizadas, matizar o psicanalista incluído na tradição inglesa como aquele que assim reconhece-se pela (re)afirmação direta do discurso e do espaço de ordem que o constitui primando em dizer o que é; e o lacaniano como aquele que subjetiva-se pela contraposição, pela negativa em relação a um outro - primando em dizer o que não é3. Passemos ao tema seguinte tendo em mente este argumento.

\section{A psicanálise}

Acerca da psicanálise (como a conheceram, quais impressões dela tiveram e têm, que mudanças houve nessa relação - se houve, etc.) os entrevistados vinculados à IPA a caracterizaram sobremaneira como um processo terapêutico cujo principal componente é o (auto) conhecimento, ou ainda, uma aprendizagem objetivada mediante a relação com um outro e que se presta a um sentir-se melhor e a tratar um sofrimento.

Assim Vilma coloca que "a psicanálise dá esse recurso, porque o que ela oferece é a gente abrir a mente, e o contato com o outro é uma forma de conhecimento também, tem que ser terapêutica também, ninguém vai para o psicanalista só pra se conhecer, vai também pra se sentir melhor, né".

\footnotetext{
${ }^{3} \mathrm{O}$ que almejamos marcar aqui são os efeitos mais recorrentes nas falas de cad grupo, isto é, os modos de subjetivação prevalecentes. Dado que, pontualmente, os entrevistados dos dois grupos fazem recurso a ambos os modos de subjetivação delineados, isto é, eventualmente os lacanianos reafirmam o mesmo e os membros da IPA contrapõem-se ao outro - mas de forma pontual, não prevalecente.
}

Mario, além de subscrever o ponto de vista apresentado por Vilma, ampliará esse conhecimento/aprendizado para além da situação clínica estritamente dita:

Meu aprendizado de vida vai se refletir na minha clínica e vice-versa, porque, como eu te falei, cada vez que eu tô convivendo com uma pessoa durante um tempo eu tô aprendendo com ela, estamos aprendendo juntos. [...] Agora, você tá aprendendo com o sofrimento, você tá sempre diante de alguém que tem um sofrimento, né, senão ele não estaria dentro de um consultório de um analista.

A psicanálise configura-se em seus discursos como um procedimento relacional que decanta um conhecimento, uma aprendizagem ou, diríamos ainda, um saber funcional. $\mathrm{O}$ entrevistado da IPA, ao praticar sua psicanálise relacionando-se, precipita um saber (e uma verdade), produzindo um conhecimento direcionado a determinados fins. Sendo, ainda, nessa e por essa prática que ele se reconhecerá psicanalista. A psicanálise, aqui, dá-se através de um movimento de afirmações diretas, objetivando algo (um saber), numa positividade.

Ao falar sobre o mesmo tema o discurso dos entrevistados lacanianos toma direção diversa: quando comentam como se deu a escolha pela psicanálise (em que momento aconteceu, que fatores foram fundamentais para tanto, etc.) Ricardo e Larissa mencionam, respectivamente, "fisgadas" e "encantos" imediatos nos primeiros contatos. Estes dois entrevistados trazem personagens capitais em seus processos de escolhas (o Professor D. de Larissa; e uma pessoa com palavra de autoridade, no caso de Ricardo) e, a esses personagens, associam uma verdade: "essa pessoa ela tava investida de uma autoridade [...] algum traço que tinha nessa pessoa que me relançou a retomar a minha questão lá do início [...] com uma verdade que existe, que eu tenho certeza que existe" (Ricardo). A escolha pela psicanálise dandose em relações nas quais a verdade encantada no outro é decantada no entrevistado. Ainda segundo Ricardo:

Psicologias do eu eram como se, elas tratavam do efeito apenas, e eu queria, e a psicanálise eu observava que tinha causas, e que tinham estruturas, que tinham funcionamentos mentais inconscientes, que determinavam aquele tipo de comportamento, né. E essas teorias todas, essas escolas todas, eu via que tinha, claro, até um ponto de verdade no que elas falavam, mas que não era consistente assim né, tinha muito mais.

Larissa, quando discorre sobre os primeiros contatos com a psicanálise, conta que

surgia um discurso diferente dos outros professores que falavam em história da psicologia, em desenvolvimento... A psicanálise sempre tem um outro tom de falar das coisas. Não fica só naquela superficialidade do comportamento, vai mais afundo, vai além disso. [...] O Professor D. ele tinha uma forma de abordar os textos que levava pra ler que se aprofundava, não ficava só na linha a linha. Então isso me parecia como, é, "nossa, ele entende além das coisas, a psicanálise dá a ferramenta pra você ir além dessa superficialidade, da aparência" né. [...] A aparência é ilusória, isso que você consegue atingir, que vai por trás que seria o verdadeiro.

Fractal, Rev. Psicol., v. 28 - n. 2, p. 275-284, 2016 
Temos a montagem de uma cena na qual a psicanálise e outros discursos conflitam, sendo predominantemente através dessa dualidade conflitante que a psicanálise toma forma: ela distingue-se por ser capaz de um aprofundamento em relação à superficialidade do comportamento; capacidade que a coloca em estreita relação com a verdade e que deixa o discurso oposto associado à aparência. Para além do que dizem, salientamos como dizem: através de um jogo de contraposição em que a psicanálise é dita enquanto algum outro é desdito. Trata-se, segundo nossa análise, de uma diferenciação constituinte, em que a psicanálise é objetivada indiretamente: mediante a diferenciação e oposição a outro discurso - numa negativa.

$\mathrm{Na}$ cisão que atravessa e constitui o discurso dos entrevistados lacanianos a psicanálise distingue-se por opor-se ao dito falso; tendo "algo mais" em relação aos outros discursos. O psicanalista, assim, é feito e faz-se desiludido, profundo e como alguém que busca distanciar-se do ilusório e dos efeitos, seja por estar além das aparências, seja por estar junto ao engenho dos funcionamentos determinantes. Psicanalista e psicanálise fazem-se não somente no reconhecimento e legitimação de um campo dito verdadeiro, mas especialmente numa contraposição destituinte do dito falso.

Avancemos mais um passo rumo ao nosso objetivo, a saber, o psicanalista em seus efeitos de reconhecimento e desconhecimento, em seus modos de subjetivação.

\section{O psicanalista}

Ao responder sobre aquilo que consideram necessário para ser um psicanalista e poder falar em nome da psicanálise os entrevistados do grupo da IPA mencionam em suas falas principalmente os requisitos institucionais. Conforme Mario:

Pra poder falar em nome da psicanálise? Eu considero necessário seguir essas orientações que instituições determinam pra pessoa se formar como psicanalista. [...] Agora, realmente a gente precisa ter uma formação, até porque algumas pessoas precisam saber como vão se nortear. Não pode virar uma anarquia. [...] Eu acho que essas regulamentações que a IPA coloca dão um bom subsídio pra pessoa.

\section{E conforme Vilma:}

É, fazer essa formação do modo que é solicitado, né, isso é uma coisa básica. E se alinhar com certas questões institucionais [...] um psicanalista primeiro tem que ser uma pessoa que seja extremamente dedicada, né, não pode ser uma pessoa com um distúrbio grave de personalidade, não pode ser um psicopata, por exemplo, eàs vezes é muito dificil perceber esse tipo de personalidade. Então uma triagem, assim, né, a pessoa passa por várias entrevistas, é muito importante pra uma instituição receber aquela pessoa.

Os integrantes do grupo associado à IPA afirmam sem reticências a necessidade da filiação institucional, isto é, a necessidade de o psicanalista se formar segundo as diretrizes e programações estipuladas pela IPA. É, como já mencionado, pela observância às normas institucionais que estes entrevistados reconhecem o advento do psicanalista. Assim, para os participantes desta pesquisa, o modelo de formação da IPA certifica o psicanalista - em seu norteamento, subsídios, dedicação, tipo de personalidade, etc. -, garantindo-o. $\mathrm{Na}$ /pela sujeição ao espaço de ordem organizado pela IPA (e reproduzido em seus discursos) os entrevistados reconhecem-se na legítima posse de um lugar de fala psicanalítico.

Principal decorrência desta organização de requisitos: o psicanalista existe. Existe de forma direta e afirmativa. Ele está garantido por um/num modelo de formação que é reinvestido por seu produto (o psicanalista). Efeito maior desta ordenação discursiva (e ponto de apoio para nossas conjecturas): diante da pergunta "você se considera um psicanalista?" todos os entrevistados filiados à IPA reconhecem-se, sem rodeios, como tal - regra nenhuma é infringida nessa afirmação, muito pelo contrário, são acatadas.

Por sua vez, quando indagados acerca dos requisitos para a posse de um lugar de fala psicanalítico, os entrevistados lacanianos trazem diversos elementos, destacando a análise pessoal. Assim, antes de falar o que é, Ricardo fala o que o psicanalista não é:

Ah, o psicanalista, ai tá uma questão. É, o psicanalista, eu vejo que não é uma produção em série assim, né, que "ah eu vou ser um psicanalista", isso é de um ideal assim, né. A gente quer ser muitas coisas quando é criança, quando é adolescente, e muita gente vive numas situações ai totalmente equivocadas porque não é bem aquilo que ela queria, é uma coisa que quiseram por ela, ela tá ali né, é, presa naquela, digamos uma alienação, e uma outra coisa né, que não era ela. Mas assim, a psicanálise eu vejo assim, que pra ser um psicanalista é fundamental que a pessoa passe por uma análise, [...] e daí, vai se saber se é analista ou não no final dessa experiência, se não chegar ao final não, né.

Assim, para Ricardo, tal como para os entrevistados filiados à IPA, o psicanalista resulta de um processo; neste caso, não o de uma formação permeada pelos rituais de uma escola de formação, mas, de uma vivência pessoal: a análise. Ser psicanalista configura-se, pois, como uma descoberta, mais do que um resultado. Beatriz, por sua vez, recorrerá novamente à noção de "falta" para expressar aquilo que o psicanalista tem que ter em meio ao que ele não é e não pode dizer:

Nunca é, né. Acho que tem que ter muita vontade, tem que ter empenho [...] Não posso chegar um dia e dizer "pronto! Pronto, deu”, não dá né. Acho que isso é, isso é a morte da psicanálise, isso é a morte de um psicanalista, "agora sei tudo". Se eu disser assim "olha Renee, agora eu sei tudo", eu deixei de ser psicanalista, né, porque dai eu parei de considerar a falta.

Alguns destaques à fala de beatriz: anteriormente alusões a um possível fim de formação foram equiparadas a "ter tudo", agora ser psicanalista é equiparado a "saber tudo". E, de acordo com a entrevistada, levar em consideração a falta é reconhecer não poder saber tudo (sendo a falta, então, um impeditivo de uma totalização do saber); mas, paradoxalmente, a falta funciona também como totalidade fora da qual psicanálise e psicanalista não podem existir. Com a falta nunca é, sem a falta não pode existir. 
O elemento mais reconhecido pelos entrevistados deste grupo como imprescindível para que alguém possa ser psicanalista é a análise pessoal. Conjuntamente existem menções à vontade, ao empenho, à falta, dentre outros. Entretanto, apesar da diversidade de elementos, os requisitos identificados por estes entrevistados são apresentados do mesmo modo, ou seja, são colocados em oposição a outros elementos (a ideais, alienações, saber tudo, etc.). Novamente, o discurso dos lacanianos dar-se-á, prioritariamente, num jogo de contrastes constitutivos, no qual o psicanalista, quando afirmado, o é pela diferenciação a um outro.

Decorrência, segundo nossa análise, desta organização discursiva: o psicanalista não pode existir como tal deliberadamente. Ao que tudo indica, quando constituído num e por um jogo de contrastes o psicanalista vai afirmar-se em relação a outros elementos, dependendo, então, desta contraposição para legitimar, em termos, seu lugar de fala como psicanalítico. Semelhante organização discursiva gera o efeito de não reconhecimento de si mesmo como psicanalista: diante da pergunta "você se considera um psicanalista?" dos 3 entrevistados, Ricardo e Larissa não se reconhecem como tais, afirmando que dependem de algumas condições para sê-lo: "Não, de jeito nenhum [...] Agora se eu vou ser ou não isto só o tempo vai dizer. Se esse é o meu desejo e se vai ser forte o suficiente pra chegar lá" (Ricardo); "Geralmente eu falo que sou psicóloga, eu não falo que sou psicanalista. Acredito que me falta ainda muito estudo pela frente" (Larissa), enquanto Beatriz reconhece-se como tal parcialmente, evidenciando a dualidade de seu discurso em seu autorreconhecimento:

Por uma certa medida me considero psicanalista, em outra não [...]. Talvez assim, pra fora né, pras pessoas que não são psicanalistas eu posso dizer "quê que faz? Psicanálise né”, mas pra dentro não, claro, né, num sentido mais honesto assim não, mais nesse sentido de formação, né.

Até aqui marcamos as especificidades do discurso de cada grupo, as características que os fazem irredutíveis. No entanto, em meio às diferenças também existem pontos de convergência. Sendo o principal deles a centralidade atribuída à análise pessoal no processo de formação.

\section{A Análise Pessoal: dispositivo privilegiado de produção do psicanalista}

Deparamo-nos agora com o elemento central dos discursos dos entrevistados. Elemento com o qual nossa perspectiva (da formação psicanalítica) foi diversas vezes igualada, conforme aponta Ricardo: "A formação é no divã, na própria análise pessoal". Seja como requisito para se tornar psicanalista, componente do processo de formação ou da escolha pela psicanálise, o fato permanente é a centralidade da análise pessoal como dispositivo produtor do psicanalista - em ambos os grupos.

De acordo com os entrevistados, é via análise pessoal que o psicanalista advém. $\mathrm{E}$ isso acontece enquanto a própria psicanálise se faz. Trata-se de um dispositivo curioso, pois nele a formação se dá enquanto o futuro psicanalista está no papel de paciente, numa sobreposição de lugares. O psicanalista é, pois, feito ao mesmo tempo em que articula verdades pessoais através do principal dispositivo discursivo-institucional elaborado pela psicanálise.É sujeitando-se a este discurso, reconhecendose intimamente através dele e experimentando seus efeitos em si mesmo que o psicanalista poderá articulá-lo a um outro: "Dai quando me submeti a minha análise pessoal e percebi o quanto aquela atividade me ajudava na minha vida, eu passei a ter interesse em dirigir isso pra outras pessoas também" (Mario). O sujeito-paciente institui e inaugura o sujeito-psicanalista. O psicanalista faz, ainda, mais do que se (re)conhecer e se formar quando submete-se a uma análise, ele reitera a própria psicanálise como dispositivo funcional e crível: "a gente tem que ter certeza de que funcionou em pelo menos um, né, que foi a gente [...] Então, tem que acreditar em alguma coisa: na psicanálise" (Beatriz). A psicanálise objetiva-se por meio da subjetivação do psicanalista como paciente e vice-versa.

Retomando os postulados teóricos apresentados anteriormente, remetemos à relação de interioridade existente entre um dado dispositivo discursivoinstitucional e o sujeito por ele produzido (que é, também, seu produtor). Oras, tomando a análise pessoal como dispositivo discursivo-institucional e o psicanalista como seu sujeito produzido/produtor temos, em última instância, o processo de produção de um sujeito capaz de recondicionar o dispositivo que o produziu por meio dos efeitos subjetivos - dos efeitos de reconhecimento e desconhecimento - ali disparados.

Tendo em vista essa relação de interioridade, não pudemos deixar de notar o quão largamente os efeitos exercidos pela psicanálise sobre os psicanalistas entrevistados são por eles reconhecidos em seus discursos. Os entrevistados de ambas escolas discorrem sobre como a formação (via análise pessoal) os amadureceu, mudou suas perspectivas, os fez perder preconceitos, se desalienarem, se libertarem e assim por diante. Por outro lado, e paralelamente, os efeitos que esses psicanalistas exercem sobre a psicanálise (ou seja: o quanto contribuem para legitimá-la como tal) ficam num relativo desconhecimento, embora estejam mostrados em seus discursos.

Ricardo, quando discorre sobre a psicanálise que reconhece como legítima - a que nomeia freudiana e que é única - o faz equiparando a psicanálise freudiana à lacaniana, de modo a emprestar a legitimidade da primeira à segunda:

$E$ É eu vejo assim que a psicanálise freudiana, ela sempre foi a psicanálise. Porque tem psicanálises ai que não são freudianas [...]. Na verdade o Lacan, ele simplesmente colocou termos que o Freud não colocou daquela forma, mas que também estão na teoria. Por exemplo, o sujeito, Freud não falou do sujeito, sujeito do inconsciente quem fala é o Lacan. Mas o Freud fala em toda a sua obra do sujeito quando ele trata do inconsciente. O que é o sujeito? É o inconsciente [...] Mas as psicanálises, eu vejo assim que existe uma psicanálise, que é a freudiana, e formas de, estilos de cada psicanalista ou analista, seu estilo próprio de atuar né, muito particular. Não digo que com isso vai se 
inventando né, novas linhas, novas formas de trabalhar, não.

Ricardo sobrepõe autores e conceitos distintos e reafirma a existência de somente uma linha, uma forma de trabalhar, enfim, de somente uma psicanálise. Para além das justificativas teóricas que o "retorno à Freud" elaborado por Lacan possa vir a prestar, temos menções a diferenças fundamentais colocadas sob o crivo de reconhecimento de uma unidade. Ricardo faz reconhecer uma continuidade onde seu discurso, ao mesmo tempo, demonstra descontinuidades para que sua prática seja tida como freudiana e, portanto, legítima. Ele reconhece seu próprio assujeitamento à psicanálise freudiana, mas faz desconhecer as alterações que ele próprio (como lacaniano) endossa e subscreve na psicanálise elaborada por Freud ("Que que é o sujeito? É o inconsciente").

Mario, ao descrever como entende que um processo de formação deva ser, afirma:

\section{Ah, como eles orientam que é pra ser mesmo, né. Geralmente isso tem normativos que regem esse tipo de formação [...]. Da experiência que eu tive eu só posso estar de acordo. Penso que isso tá baseado em 4, alguns dizem tripé, outros dizem: análise pessoal, supervisão, atividade clínica $e$ estudo teórico-clínico. [...] E eu ainda acrescentaria, além desses quatro fatores, a experiência de vida, né, que eu penso que a experiência de vida da pessoa é fundamental pra exercer a psicanálise.}

Apesar de colocar-se na estrita adesão à norma do modelo do qual participa ("só posso estar de acordo"), Mario não hesita em reordená-lo dando ao tripé da formação um quarto e, ainda, um quinto elemento. Ele confirma sua adesão ao modelo clássico, coloca-o como sendo o único de seu conhecimento e como necessário, mas, no mesmo ato, modifica-o ao incluir sua experiência de vida como um dos fundamentos do processo de formação; isso tudo enquanto faz-se reconhecer de acordo com as prescrições institucionais. No reconhecimento do instituído Mario faz desconhecer o próprio ato instituinte.

A manutenção de uma unidade (no caso de Ricardo) e de uma ordem (no caso de Mario) é que tomam primeiro plano no discurso desses entrevistados. Necessita-se reproduzir um discurso unificado e ordenado que o próprio discurso dos entrevistados não sustenta sem contradições.

Consideramos, com Foucault (1984, p. 91), que todo e qualquer modo de subjetivação faz-se mediante um jogo de assujeitamento e resistência a um discurso: “onde há poder há resistência e, no entanto (ou melhor, por isso mesmo) esta nunca se encontra em posição de exterioridade em relação ao poder". Se assim é, se resistência e sujeição acontecem conjuntamente, nos avizinhamos de um modo de subjetivação explícito com relação aos seus assujeitamentos e discreto com relação às suas resistências. Como já dito, os psicanalistas entrevistados reconhecem amplamente os efeitos do discurso psicanalítico sobre eles mesmos, mas pouco reconhecem dos efeitos que exercem sobre tal discurso.

Indagando a timidez desses movimentos de resistência arriscamos formular que reconhecê-los pode ser arriscado, imprevisível e, quem sabe, intempestivo para quem se propõe psicanalista - e assim é, via de regra, para todo integrante de qualquer comunidade discursiva. Afinal reconhecer resistências significa assumir rupturas e mudanças decorrentes, colocando em risco não somente o reconhecimento de si mesmo como psicanalista, como também da prática que se exerce, expondo-a a não ser reconhecida como psicanalítica por não estar de acordo com os termos instituídos. E isto se sustenta no e pelo discurso dos entrevistados de ambos os grupos. Eis "o que há, enfim, de tão perigoso no fato de as pessoas falarem e de seus discursos proliferarem indefinidamente". (FOUCAULT, 2008, p. 8).

\section{Considerações Finais}

A guisa de conclusão recolocamos nosso objetivo, qual seja, de investigar possíveis modos de subjetivação na formação em psicanálise. Assim, pudemos assinalar algumas especificidades nos discursos de cada grupo: no caso dos entrevistados ligados à IPA, naquilo que atualizam sobre a observância às normas institucionais e às programações propostas, temos uma formação cujo efeito subjetivo preponderante é a reafirmação direta do espaço de ordem que os faz psicanalistas; subjetiva-se psicanalista pela reafirmação do discurso objetivador. No caso dos entrevistados lacanianos, naquilo que atualizam sobre afirmar a psicanálise pela diferenciação a outros termos, temos uma formação cujo efeito subjetivo preponderante é uma contraposição constitutiva do próprio discurso mediante a distinção a outro; subjetivase psicanalista pela contraposição a outros discursos. Especificidades estas que se dão num quadro regular marcado por uma condição geral para a produção do psicanalista: a análise pessoal.

Entre especificidades e regularidades pôde-se destacar ainda o reconhecimento dos processos de sujeição do psicanalista à psicanálise; reconhecimento carregado dum relativo desconhecimento acerca do quanto a psicanálise é também, ela própria, recondicionada pelas acentuações que esses psicanalistas lhe atribuem em suas práticas cotidianas. De modo a, ao final desta experiência, concluir algo que talvez soe óbvio: a psicanálise figura como condição-limite do psicanalista e vice-versa. Mas eis que, se o óbvio pôde ser problematizado, nosso objetivo foi satisfatoriamente cumprido.

Finalmente, ressaltamos a parcialidade de nossas conclusões: não foi do escopo de interesses deste estudo a generalização de dados e afirmações. Mas antes, o delineamento pautado nos discursos analisados, nas regularidades e singularidades que neles puderam ser destacadas. Quaisquer pretensões generalizantes demandariam outros estudos, com amostras significativamente maiores; correndo, ainda assim, o risco de incorrer em redução e simplificação do quadro. Talvez por isso possamos dizer que o intento de um estudo como o nosso não pende, radicalmente, em direção a uma espécie de explicação total, e sim a proporcionar ocasião para fazer pensar - pensar e problematizar, como dito acima, o óbvio, o sedimentado, o naturalizado... 
aquilo que, pela repetição, já não faz pensar! Afinal, endossamos Foucault (2009a, p. 28), “o saber não é feito para compreender, ele é feito para cortar".

\section{Referências}

ALBUQUeRQUE, J. A. G. Metáforas da desordem. Rio de Janeiro: Paz e Terra, 1978

BLEGER, J. Psicohigiene e psicologia institucional. Porto Alegre: Art. Médicas, 1984.

DASSOLER, V. A. Formação psicanalítica, instituição e possibilidades transferenciais. Revista da Associação Psicanalítica de Porto Alegre, Porto Alegre, n. 29, p. 73-79, 2005.

FOUCAULT, M. História da sexualidade: a vontade de saber. Rio de Janeiro: Graal, 1984. v. 1.

FOUCAULT, M. O sujeito e o poder. In: DREYFUS, H. L.; RABINOW, P. Michel Foucault, uma trajetória filosófica: para além do estruturalismo e da hermenêutica. Rio de Janeiro: Forense Universitária, 1995. p. 231-249.

FOUCAUlT, M. A ordem do discurso. São Paulo: Loyola, 2008.

FOUCAULT, M. Nietzsche, a genealogia e a história. In: MACHADO, R. (Org.). Microfisica do poder. Rio de Janeiro: Graal, 2009a. p. 15-37.

FOUCAULT, M. Sobre a história da sexualidade. In: MACHADO, R. (Org.). Microfísica do poder. Rio de Janeiro: Graal, 2009b. p. 243-76.

GUIRADO, M. Psicologia institucional. São Paulo: EPU, 1986.

GUIRADO, M. Psicanálise e análise do discurso: matrizes institucionais do sujeito psíquico. São Paulo: Summus, 1995.

GUIRADO, M. A clínica psicanalítica na sombra do discurso: diálogos com aulas de Dominique Maingueneau. São Paulo: Casa do Psicólogo, 2000.

GUIRADO, M. A análise institucional do discurso como analitica da subjetividade. São Paulo: Annablume, 2010.

LAPASSADE, G. Grupos, organizações e instituições. Rio de Janeiro: Francisco Alves, 1977.

MAINGUENEAU, D. Novas tendências em análise do discurso. Campinas: Pontes, 1997.

NICOLACI-DA-COSTA, A. M. O campo da pesquisa qualitativa e o Método de Explicitação do Discurso Subjacente (MEDS). Psicologia: Reflexão e Crítica, Porto Alegre, v. 20, n. 1, p. 65-73, 2007.

RIBEIRO, C. R. Sujeito-dobradiça: metáfora de subjetividade, metonímia institucional. In: GUIRADO, M.; LERNER, R. (Org.). Psicologia, pesquisa e clínica: por uma análise institucional do discurso. São Paulo: Annablume: Fapesp, 2007. p. 245-262.

SARAIVA, L. A.; NUNES, M. L. T. A supervisão na formação do analista e do psicoterapeuta psicanalítico. Estudos de Psicologia, [S.1.], v. 12, n. 3, p. 259-268, 2007.
VIARO, R. V.; VALORE, L. A. Método, análise e verdade em Psicologia: sobre uma análise institucional do discurso. Psicol. cienc. prof., Brasília, v. 31, n. 4, p. 718-733, 2011. Disponível em: <http://www.scielo.br/scielo.php?script=sci arttext\&pid=S1414-98932011000400005\&lng=en\&nrm=iso>. Acesso em: 12 jul. 2013.

Recebido em: 12 de agosto de 2013 Aceito em: 16 de julho de 2015 